\title{
Substituição parcial do farelo de soja por ureia ou amireia na alimentação de cabras em lactação
}

\author{
Clayton Quirino Mendes ${ }^{1}$, Raquel Helena Rocha Fernandes ${ }^{1}$, Ivanete Susin ${ }^{2}$, Alexandre $^{2}$ \\ Vaz Pires ${ }^{2}$, Renato Shinkai Gentil ${ }^{1}$
}

\footnotetext{
${ }^{1}$ Pós-graduação em Ciência Animal e Pastagens - ESALQ/USP - Piracicaba, SP.

2 Departamento de Zootecnia - ESALQ/USP - Piracicaba, SP.
}

RESUMO - Trinta e três cabras leiteiras foram utilizadas para avaliar o efeito da substituição parcial do farelo de soja por ureia ou amireia (ureia + milho extrusado) sobre a produção e composição do leite e a concentração plasmática de glicose, nitrogênio ureico e ácidos graxos não-esterificados. Os animais foram distribuídos em delineamento de blocos completos casualizados, com três dietas experimentais e onze repetições. As dietas experimentais, todas isonitrogenadas, foram compostas de $40 \%$ de silagem de milho e $60 \%$ de concentrado e diferiram apenas quanto às fontes nitrogenadas (farelo de soja, farelo de soja $+2,8 \%$ de amireia ou farelo de soja $+1,5 \%$ de ureia). As fontes nitrogenadas utilizadas nas dietas não influenciaram o consumo de matéria seca, a produção de leite, a produção de leite corrigida para 3,5\% de gordura, nem os teores de gordura e proteína no leite. A concentração de glicose e ácidos graxos não-esterificados no plasma não foi alterada pela fonte de nitrogênio. Entretanto, a concentração de nitrogênio ureico plasmático na colheita após a quarta semana experimental foi menor nos animais que receberam o farelo de soja. A concentração plasmática de glicose, nitrogênio ureico e ácidos graxos não-esterificados foi semelhante entre as fontes de nitrogênio não-proteico, independentemente da forma utilizada. $\mathrm{O}$ uso da ureia na forma extrusada (amireia) não apresenta vantagem em relação à ureia utilizada na forma convencional.

Palavras-chave: caprinos, fontes proteicas, nitrogênio não-proteico, produção de leite

\section{Partial replacement of soybean meal by urea or starea for lactating dairy goats}

\begin{abstract}
Thirty-three dairy goats were used to evaluate the effects of partial replacement of soybean meal by urea or starea (urea + extruded corn) on milk production and composition and plasma glucose, urea nitrogen and nonesterified fatty acids concentrations. The animals were distributed in a randomized complete block design, with three experimental diets and eleven replicates. All the experimental diets were isonitrogenous, composed by $40 \%$ corn silage and $60 \%$ concentrate, with different nitrogenous sources (soybean meal, soybean meal $+2.8 \%$ starea or soybean meal $+1.5 \%$ urea). The nitrogenous sources used in the diets did not influence dry matter intake, milk production, milk production corrected for $3.5 \%$ fat-corrected milk, neither milk fat and protein contents. Plasma glucose and non-esterified fatty acids concentrations were not modified by nitrogen sources. However, plasma urea nitrogen concentration in the harvest after the fourth experimental week was lower for animals fed soybean meal diet. Plasma concentration of glucose, urea nitrogen and non-esterified fatty acids were similar among non-protein nitrogen sources, regardless to the way it was used. Urea used in the extruded form (starea) has no advantage compared to the urea used in the conventional form.
\end{abstract}

Key Words: goats, milk production, non protein nitrogen, protein sources

\section{Introdução}

A alimentação de caprinos leiteiros mantidos em sistema intensivo é responsável pela maior parte dos custos de produção. Geralmente, os suplementos proteicos de origem vegetal, como o farelo de soja, apresentam preço mais elevado e contribuem para aumentar o custo com alimentação. Dessa forma, fontes de nitrogênio não proteico (NNP) têm sido utilizadas como alternativa para atender às exigências proteicas dos animais e reduzir o custo de produção (Huber et al., 1967).
Na maioria dos trabalhos revisados por Santos et al. (1998a) a inclusão da ureia na alimentação de vacas leiteiras não alterou o consumo de matéria seca e a produção e composição do leite, indicando que esta pode ser utilizada para reduzir os custos de produção, desde que seja combinada com fontes de proteína verdadeira. Entretanto, quando se compara trabalhos nacionais avaliando o uso da ureia em substituição ao farelo de soja, os resultados são controversos (Oliveira et al., 2001; Imaizumi et al., 2006; Pina et al., 2006; Aquino et al., 2007; Guidi et al., 2007). 
A amireia, produto da extrusão da ureia com amido, foi desenvolvida com o objetivo de criar uma fonte de ureia de liberação mais lenta que a ureia convencional (Helmer \& Bartley, 1970; Roman-Ponce et al., 1975). Teoricamente, a fonte de NNP com liberação lenta de amônia oferece vantagens por aumentar a disponibilidade da amônia na síntese microbiana e reduzir sua toxidez (Bartley \& Deyoe, 1975). Além disso, essa prática aumenta a velocidade de fermentação do amido no rúmen, compatibilizando os dois fatores na síntese de proteína microbiana (Silva et al., 1994), podendo alterar aspectos produtivos, como a produção e a composição do leite.

Resultados controversos foram observados com a utilização da amireia em substituição à ureia para animais em lactação. Helmer et al. (1970) relataram melhores resultados na produção e na composição do leite para os tratamentos de farelo de soja ou amireia em detrimento ao premix com ureia. Por outro lado, Carmo et al. (2005) e Silva (2007) não observaram diferença na produção de leite ao substituírem parcialmente farelo de soja por ureia ou amireia na dieta de vacas e cabras em lactação, respectivamente.

Este trabalho teve como objetivo avaliar a substituição parcial do farelo de soja pela ureia ou pela amireia na alimentação de cabras em lactação sobre o consumo de matéria seca, a produção e a composição do leite e a concentração plasmática de glicose, nitrogênio ureico e ácidos graxos não-esterificados.

\section{Material e Métodos}

O experimento foi realizado nas instalações do Sistema Intensivo de Produção de Ovinos e Caprinos do Departamento de Zootecnia da Escola Superior de Agricultura "Luiz de Queiroz" da Universidade de São Paulo.

Foram utilizadas 33 cabras (12 primíparas e 21 multíparas) das raças Saanen e Pardo-Alpina com $110 \pm 6$ dias em lactação, alojadas em baias individuais do tipo tie-stall $(0,5 \times 1,2 \mathrm{~m})$, em galpão coberto, com piso ripado, providas de comedouro individual e bebedouro. Os animais foram alimentados uma vez ao dia com ração total, sempre após a ordenha da tarde, permitindo sobras correspondentes a $10 \%$ do total oferecido. O volumoso e o concentrado foram pesados separadamente e homogeneizados manualmente no cocho. As dietas foram compostas de $40 \%$ de silagem de milho e $60 \%$ de concentrado (Tabela 1). Na dieta controle (farelo de soja), a principal fonte de nitrogênio foi o farelo de soja, o qual foi substituído parcialmente por amireia $150 \mathrm{~S}$ $(2,8 \%$ da MS) ou ureia $(1,5 \%$ da MS $)$. As dietas, isonitrogenadas e isoenergéticas, foram formuladas para atender ou exceder as exigências de cabras em lactação (NRC, 1981). O período experimental teve duração de oito semanas. Os animais foram submetidos a um período préexperimental com duas semanas de duração para adaptação às instalações e avaliação da produção de leite. Além disso, no final do período pré-experimental, as cabras foram pesadas por três dias consecutivos após a ordenha da manhã, para obtenção do peso corporal médio.

O consumo diário de matéria seca foi obtido por meio da diferença entre a quantidade de matéria seca fornecida e as sobras. As amostras colhidas semanalmente foram conservadas a $-18^{\circ} \mathrm{C}$ e posteriormente descongeladas, fracionadas e mantidas em estufa com ventilação forçada a $55^{\circ} \mathrm{C}$ por 72 horas. Em seguida, foram processadas em moinho tipo Wiley providos de peneiras com crivos de $1 \mathrm{~mm}$ e utilizadas para a determinação da matéria seca, matéria orgânica, extrato etéreo e proteína bruta de acordo com AOAC (1990). A análise de fibra em detergente ácido foi realizada segundo Van Soest (1963) e a fibra em detergente neutro de acordo com Van Soest et al. (1991).

As cabras foram ordenhadas duas vezes ao dia ( $7 \mathrm{~h} 30$ e $15 \mathrm{~h} 30$ ), sendo a produção de leite determinada por pesagem semanal. Amostras de leite compostas (ordenha da manhã e da tarde) foram colhidas semanalmente, no dia da pesagem. As amostras foram conservadas em 2-bromo2nitropropano-1-3-diol sob refrigeração $\left(6^{\circ} \mathrm{C}\right)$ para posterior determinação de proteína, gordura, lactose e sólidos totais. As determinações foram realizadas por leitura de absorção de infravermelho próxima em

Tabela 1 - Composição das dietas experimentais

\begin{tabular}{lccc}
\hline & \multicolumn{3}{c}{ Dieta experimental } \\
\cline { 2 - 4 } & $\begin{array}{c}\text { Farelo } \\
\text { de soja }\end{array}$ & $\begin{array}{c}\text { Farelo de } \\
\text { soja+amireia }\end{array}$ & $\begin{array}{c}\text { Farelo de } \\
\text { soja+ureia }\end{array}$ \\
\hline Composição em ingredientes & & & \\
Silagem de milho & 40,10 & 40,10 & 40,10 \\
Milho moído & 29,90 & 37,20 & 38,50 \\
Farelo de soja 48\% & 17,30 & 7,20 & 7,20 \\
Suplemento mineral ${ }^{1}$ & 2,40 & 2,40 & 2,40 \\
Caroço de algodão & 10,30 & 10,30 & 10,30 \\
Amireia & - & 2,80 & - \\
Ureia & - & - & 1,50 \\
Composição nutricional & \multicolumn{4}{c}{} \\
Matéria seca & 53,20 & 53,10 & 53,10 \\
Proteína bruta (\%) & 16,43 & 16,70 & 16,87 \\
Fibra detergente neutro (\%) & 36,21 & 37,16 & 36,75 \\
Fibra detergente ácido (\%) & 20,53 & 20,80 & 20,53 \\
Extrato etéreo (\%) & 4,67 & 4,83 & 4,78 \\
\hline
\end{tabular}

${ }^{1}$ Composição: cálcio - $22 \%$; fósforo - $5 \%$; magnésio - $5 \%$; enxofre $-2,2 \%$, cloro $10,6 \%$; manganês $-1.500 \mathrm{mg} / \mathrm{kg}$; ferro $-500 \mathrm{mg} / \mathrm{kg}$; zinco $-1.500 \mathrm{mg} / \mathrm{kg}$; cobre $-450 \mathrm{mg} / \mathrm{kg}$; cobalto $-50 \mathrm{mg} / \mathrm{kg}$; iodo $-40 \mathrm{mg} / \mathrm{kg}$; selênio $-20 \mathrm{mg} / \mathrm{kg}$. 
equipamento Bentley 2000, no Laboratório de Análise de Leite do Departamento de Zootecnia da ESALQ/USP. A produção de leite corrigida para 3,5\% de gordura foi calculada segundo a equação proposta por Gravert (1987): LCG $(3,5 \%)=0,4337 \mathrm{PL}+16,218$ PG, em que LCG é leite corrigido para gordura; PL, produção de leite (kg/dia); e PG, produção de gordura ( $\mathrm{kg} / \mathrm{dia})$.

Na quarta e na oitava semana do período experimental foram realizadas colheitas de sangue, imediatamente antes (T0) e três horas após o fornecimento da ração (T3), para determinação da concentração plasmática de glicose, nitrogênio ureico e ácidos graxos não esterificados (AGNE). As colheitas foram realizadas em tubos a vácuo com $5 \mathrm{mg}$ de fluoreto de sódio e $5 \mathrm{mg}$ oxalato de potássio. Imediatamente após a colheita, as amostras de sangue foram centrifugadas a $3000 \mathrm{~g}$ por 15 minutos e as amostras de plasma foram acondicionadas em tubos eppendorf e congeladas a $-10^{\circ} \mathrm{C}$ para posterior análise laboratorial.

Para determinação do nitrogênio ureico no plasma foi utilizado o método colorimétrico, adaptado para leitura em placas de microtítulo em aparelho do tipo Elisa Reader (BIO RAD) com comprimento de luz de 550 nanômetros. A concentração plasmática de AGNE foi determinada por meio da utilização de kit comercial (Wako Chemicals $\mathrm{GmbH}$, Neuss, Alemanha), adaptado para leitura em placas de microtítulo, em aparelho do tipo Elisa Reader (BIO RAD) com comprimento de luz 550 nanômetros. A análise da concentração de glicose plasmática foi realizada no autoanalisador bioquímico YSI 2700-S Biochem (Yellow Springs Instrument Co. Inc., Ohio, EUA).

O delineamento utilizado foi o de blocos casualizados, sendo os blocos definidos de acordo com raça, produção de leite na lactação anterior (multíparas), ordem de lactação e dias em lactação. Além disso, foi considerado para a formação dos blocos o peso médio corporal dos animais obtido durante o período pré-experimental. Os dados foram analisados utilizando-se o PROC MIXED (SAS, 2003). Os dados de produção e composição do leite e o consumo de matéria seca obtidos na segunda semana do período préexperimental foram utilizados como covariável. O modelo estatístico utilizado na análise dos dados pode ser descrito da seguinte forma: $\mathrm{Y}_{\mathrm{ijk}}=\mu+\mathrm{b}_{\mathrm{i}}+\mathrm{S}_{\mathrm{j}}+\mathrm{W}_{\mathrm{k}}+(\mathrm{SW})_{\mathrm{jk}}+\mathrm{e}_{\mathrm{ijk}}$, em que: $\mu=$ média geral, $b_{i}=$ efeito do bloco, $S_{j}=$ efeito do tratamento, $\mathrm{W}_{\mathrm{k}}=$ efeito de semana, $(\mathrm{SW})_{\mathrm{jk}}=$ interação entre tratamento e semana, e $\mathrm{e}_{\mathrm{ijk}}=$ efeito aleatório. As médias das tabelas foram obtidas pelo comando LSMEANS. Para as variáveis que obtiveram respostas significativas, foi aplicado o teste Tukey. Diferenças significativas foram consideradas a $5 \%(\mathrm{P}<0,05)$ e tendências até $10 \%(\mathrm{P}<0,10)$ de probabilidade.

\section{Resultados e Discussão}

O peso final das cabras não foi modificado pela fonte nitrogenada (Tabela 2). Assim como observado nesse experimento, Carmo et al. (2005) e Silva (2007) avaliaram a substituição do farelo de soja por ureia ou amireia e não obtiveram variação do peso corporal de vacas e cabras em lactação, respectivamente. Adicionalmente, Fernandez et al. (1997) relataram que o ganho de peso de cabras leiteiras em lactação não foi alterado pela utilização de NNP.

Não houve diferença no consumo de matéria seca, proteína bruta, extrato etéreo e fibra em detergente neutro durante o período experimental (Tabela 2). O consumo médio de matéria seca em relação ao peso vivo das cabras está de acordo com AFRC (1997), segundo o qual o consumo de cabras em lactação varia entre 3 e $5 \%$ do peso corporal. Assim como observado nesse experimento, Fernandez et al. (1997) utilizaram ureia na alimentação de cabras em lactação e não observaram alteração no consumo de matéria seca.

Tabela 2 - Variação do peso corporal e consumo diário de matéria seca e nutrientes

\begin{tabular}{|c|c|c|c|c|c|}
\hline \multirow[t]{2}{*}{ Item } & \multicolumn{3}{|c|}{ Dieta experimental } & \multirow[b]{2}{*}{$\mathrm{EPM}^{1}$} & \multirow[b]{2}{*}{$\mathrm{P}^{2}$} \\
\hline & Farelo de soja & Farelo de soja + amireia & Farelo de soja + ureia & & \\
\hline \multicolumn{6}{|l|}{ Peso corporal } \\
\hline Final, kg & 67,76 & 62,82 & 68,65 & 2,00 & 0,11 \\
\hline Variação, kg & 0,67 & $-0,21$ & 0,11 & 0,50 & 0,45 \\
\hline \multicolumn{6}{|l|}{ Consumo diário } \\
\hline Matéria seca, \%PV & 3,50 & 3,33 & 3,31 & 0,12 & 0,55 \\
\hline Matéria seca, $\mathrm{g} / \mathrm{kgPV}^{0,75}$ & 90,01 & 85,17 & 77,69 & 6,83 & 0,44 \\
\hline Proteína bruta, g/dia & 382,80 & 363,40 & 374,70 & 12,87 & 0,56 \\
\hline Extrato etéreo, g/dia & 108,80 & 105,50 & 106,30 & 3,73 & 0,73 \\
\hline Fibra em detergente neutro, g/dia & 843,60 & 809,90 & 816,10 & 28,96 & 0,71 \\
\hline
\end{tabular}


Da mesma forma, Carmo et al. (2005) e Silva (2007) não verificaram diferença no consumo de matéria seca quando substituíram farelo de soja por ureia ou amireia em dietas para vacas e cabras em lactação, respectivamente. Esses dados contrariam a afirmação de que a amireia 150 S é capaz de elevar o consumo de matéria seca em relação a produtos contendo ureia (Teixeira \& Salvador, 2004).

Segundo Rindsig (1977), a suplementação com ureia não deve ultrapassar $1 \%$ da matéria seca total da dieta. $\mathrm{O}$ autor relata que sempre que a substituição de proteína verdadeira por nitrogênio não proteico for superior a $30 \%$ do total de nitrogênio da dieta, esta poderá levar à redução no consumo de matéria seca. Nesse experimento, o teor de ureia utilizado correspondeu a $1,5 \%$ da matéria seca, representando $25 \%$ do nitrogênio total, não tendo sido observada redução no consumo de matéria seca. Esse valor encontra-se dentro da recomendação apresentada por Rindsig (1977), indicando que a forma de recomendação da inclusão da ureia em dietas para cabras em lactação pode ser realizada com base na substituição do teor de nitrogênio total, e não no teor da matéria seca, uma vez que este nem sempre refletirá o limite superior de substituição do nitrogênio verdadeiro da dieta. Adicionalmente, trabalhos avaliando a substituição do farelo de soja pela ureia em até $1,5 \%$ da matéria seca na alimentação de vacas em lactação não apresentaram efeito sobre o consumo de matéria seca (Aquino et al., 2007; Guidi et al., 2007).

Foi observada tendência de maior produção de leite $(\mathrm{P}=0,08)$ para os animais que receberam a dieta contendo o farelo de soja, quando comparada às dietas contendo ureia ou amireia (Tabela 3). Os resultados de trabalhos que avaliaram a substituição parcial de farelo de soja por ureia ou amireia na produção de leite são controversos. Assim como nesse experimento, Fernandez et al. (1997) e Silva (2007) não observaram diferença na produção de leite de cabras em lactação. Adicionalmente, diversos autores (Broderick et al.,1993; Carmo et al., 2005; Aquino et al., 2007; Guidi et al., 2007) não verificaram efeito da utilização de ureia ou amireia na produção de leite de vacas leiteiras. Por outro lado, ao estudarem o efeito da ureia $(0,4 \%, 0,8 \%$ e 1,2\% da MS) na alimentação de cabras leiteiras Santos \& Bose (1985), observaram que a suplementação com ureia resultou em menor produção de leite. Da mesma forma, Vilela et al. (2007) avaliaram a substituição da proteína do farelo de soja pela amireia $150 \mathrm{~S}$ em 0,33, 66 e 100\% na ração de vacas em lactação e observaram que houve diferença para produção de leite entre os teores de amireia utilizados. Esses autores concluíram que $35 \%$ é o teor ótimo de substituição da proteína do farelo de soja pela amireia.

A composição média de leite obtida nesse experimento foi semelhante entre os tratamentos. A ausência de efeito no teor de gordura demonstra que o padrão de fermentação ruminal não foi alterado pela fonte de nitrogênio utilizada. O uso de ração total facilita a incorporação de nitrogênio não proteico à dieta, minimizando efeitos na composição do leite, decorrentes de consumo seletivo. Semelhante ao ocorrido nesse experimento, Fernandez et al. (1997) e Silva (2007) não constataram diferença no teor de gordura do leite ao utilizarem nitrogênio não proteico na dieta de cabras em lactação. Experimentos com vacas leiteiras relataram maior teor de gordura para o tratamento com ureia comparado ao farelo de soja com a amireia ou ureia (Helmer et al., 1970; Roman Ponce et al., 1975; Imaizumi et al., 2002; Carmo et al., 2005). Poroutrolado, Broderick etal.(1993)e Guidi etal.(2007)

Tabela 3 - Produção e composição do leite

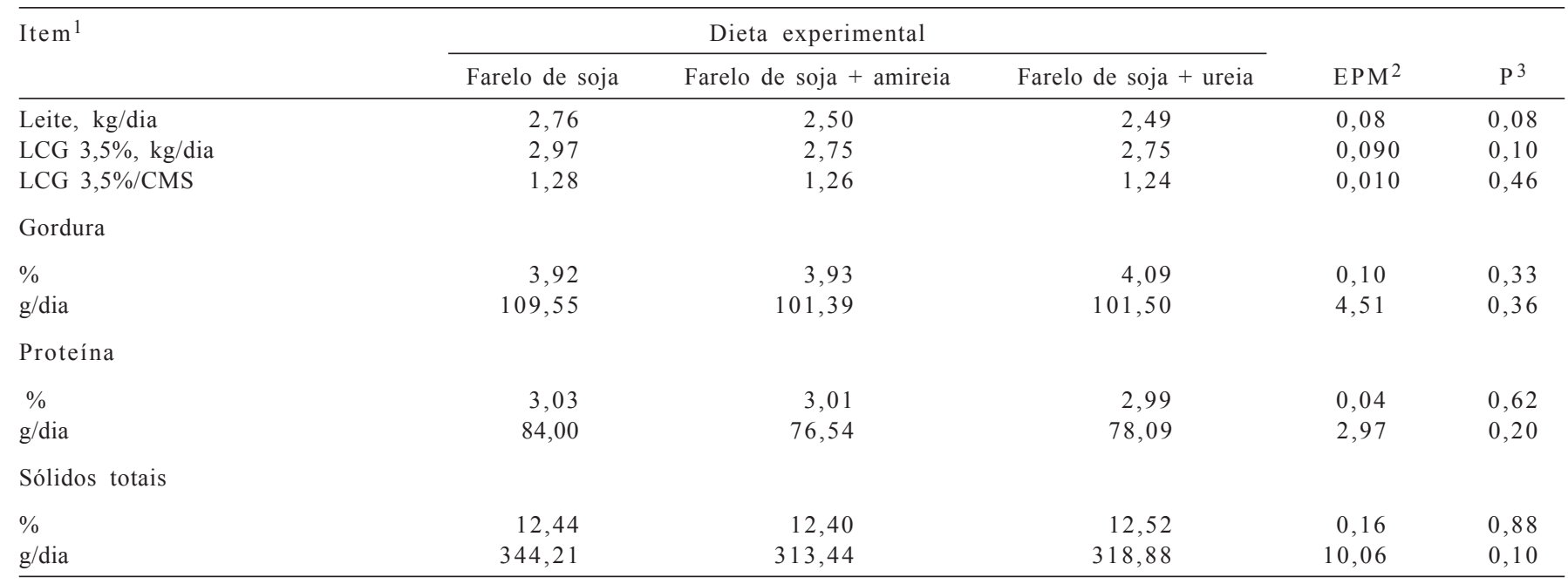

${ }^{1} \mathrm{LCG}=$ Produção de leite corrigida para $3,5 \%$ de gordura; $\mathrm{CMS}=$ Consumo de matéria seca.

${ }^{2} \mathrm{EPM}=$ Erro-padrão da média

${ }^{3} \mathrm{P}=$ Probabilidade de haver efeito das dietas $(\mathrm{P}<0,05)$. 
não encontraram efeito no teor de gordura quando incluíram ureia na dieta.

O teor de proteína do leite não foi afetado pela fonte de nitrogênio utilizada, assim como observado por Carmo et al. (2005) e Silva (2007). A ausência de alteração no teor de proteína do leite indica que não houve limitação na proteína metabolizável com o fornecimento das dietas contendo as fontes de nitrogênio não proteico. MorandFehr et al. (1991) concluíram que a fonte nitrogenada ou a concentração de proteína bruta, em dietas isoenergéticas e isonitrogenadas, tem efeito limitado em alterar a composição do leite.

Não houve diferença na concentração de glicose plasmática entre os tratamentos (Tabela 4). Segundo Santos et al. (1998b), a manipulação de fontes ou teores de proteína na dieta dificilmente afeta os teores de glicose plasmática. Diversos autores (Lu et al., 1990; Saluh et al., 1993a; Saluh et al., 1993b; Silva, 2007) avaliaram diferentes fontes e quantidades de $\mathrm{N}$ na dieta de caprinos e não relataram alterações na concentração plasmática de glicose. O mesmo foi observado para o uso de uréia (Broderick et al., 1993; Imaizumi et al., 2002) ou amiréia (Carmo et al., 2005) na alimentação de vacas leiteiras no final da lactação.
Segundo o NRC (2001), o excesso de amônia ruminal pode alterar o metabolismo de glicose. A hiperglicemia geralmente está associada à hiperamonemia, quer seja clínica ou subclínica (Fernandez et al., 1990). Nesse experimento, apesar de as concentrações de $\mathrm{N}$ ureico plasmático encontradas serem altas, acima de $24,0 \mathrm{mg} / \mathrm{dL}$, a concentração de glicose plasmática observada $(51,6 \mathrm{mg} / \mathrm{dL})$ encontra-se dentro do padrão de normalidade. Tanwar et al. (2000) encontraram valor de 50,4 mg/dL de glicose plasmática para cabras em lactação consideradas sadias e Barbosa et al. (2009) obtiveram 50,5 mg/dL para cabras da raça Alpina da primeira até a oitava semana de lactação.

De acordo com Blowey (1992), a concentração de nitrogênio ureico plasmático pode ser alterada por vários fatores, como o teor e a degradabilidade ruminal da fonte proteica da dieta. Neste estudo, verificou-se maior concentração de $\mathrm{N}$ ureico plasmático para os tratamentos contendo ureia ou amireia três horas após a alimentação quando a colheita foi realizada quatro semanas após o início do experimento. O mesmo comportamento foi observado na colheita realizada na oitava semana experimental três horas após a alimentação, no qual houve tendência $(P=0,07)$ de

Tabela 4 - Concentrações plasmáticas de glicose, nitrogênio ureico e ácidos graxos não-esterificados

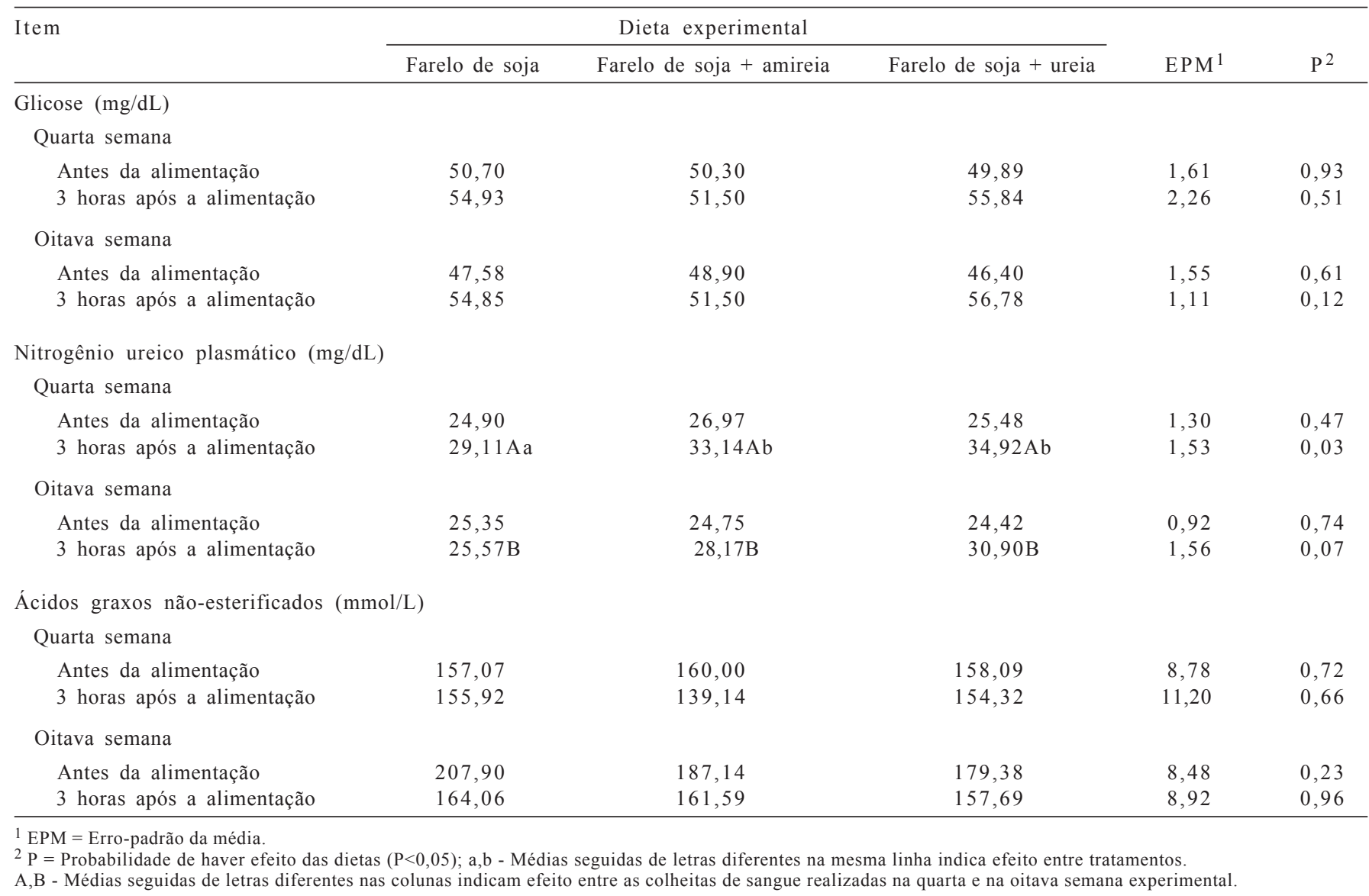


maior concentração de nitrogênio ureico plasmático para a dieta contendo as fontes de nitrogênio não proteico. Esses dados estão de acordo com Silva (2007), que avaliou a substituição do farelo de soja por ureia ou amireia na alimentação de cabras em lactação e observou que o fornecimento de fontes de nitrogênio não proteico aumentou a concentração de nitrogênio ureico plasmático em relação ao farelo de soja. Além disso, esse autor não observou diferença entre as fontes de nitrogênio não proteico. Adicionalmente, Matarazzo et al. (2006) e Guidi et al. (2007) observaram menor concentração de nitrogênio ureico plasmático, quando proteína verdadeira foi fornecida como fonte de nitrogênio para vacas em lactação.

A concentração semelhante de nitrogênio ureico plasmático para as dietas contendo ureia ou amireia, após quatro semanas, sugere que não houve variação na liberação de amônia entre as fontes de nitrogênio não proteico, indicando que não ocorreu o benefício esperado pela proteção da ureia com o milho extrusado.

Owens \& Zinn (1993) comentam que, ao fornecer dieta com ureia, ocorre diminuição na taxa de hidrólise no decorrer do tempo. Dessa forma, quando se utiliza ureia, o consumo de matéria seca e o desempenho diminuem levemente por aproximadamente um mês, retornado a valores normais após esse provável período de adaptação. No presente experimento, a concentração de nitrogênio ureico plasmático foi alta para ambos os tratamentos contendo as fontes de nitrogênio não proteico, na primeira colheita, após um mês de experimento. Já na segunda colheita, para os mesmos tratamentos, houve redução na concentração de nitrogênio ureico plasmático em relação à primeira, o que está de acordo com os autores supracitados.

A concentração plasmática de ácidos graxos não esterificados ( $\mathrm{AGNE}$ ) não foi alterada $(\mathrm{P}>0,05)$ pelas fontes proteicas. Experimentos em que diferentes fontes e quantidades de $\mathrm{N}$ foram utilizadas na dieta de cabras leiteiras também não evidenciaram alterações na concentração de AGNE (Lu et al., 1990; Saluh et al, 1993a; Saluh et al, 1993b). Os principais substratos cetogênicos em ruminantes são o butirato, absorvido através da mucosa ruminal, e os AGNE. Dessa forma, em situações de balanço energético negativo ocorre predominância de AGNE (Zammit, 1996). O fato de as cabras desse experimento não apresentarem alteração no peso vivo (Tabela 3) ou diferença na concentração de AGNE significa que as rações experimentais foram capazes de atender as exigências energéticas dessa categoria animal.

\section{Conclusões}

A utilização de ureia ou amireia em substituição parcial ao farelo de soja é uma alternativa viável para a alimentação de cabras em lactação. O uso da ureia na forma extrusada (amireia) não apresenta vantagem em relação à ureia utilizada na forma convencional.

\section{Referências}

AGRICULTURAL AND FOOD RESEARCH COUNCIL - AFRC. The nutrition of goat. Report 10. Nutrition Abstracts and Reviews, v.67, n.11, 118p. 1997.

AQUINO, A.A.; IKEDA, B.B.G.; RODRIGUES, F.S. et al. Efeito de níveis crescentes de ureia na dieta de vacas em lactação sobre a produção e a composição físico-química do leite. Revista Brasileira de Zootecnia, v.36, n.4, p.881-887, 2007.

ASSOCIATION OF OFFICIAL ANALYTICAL CHEMISTS AOAC. Official methods of analysis. 15.ed. Arlington: AOAC International, 1990. 1050p.

BARBOSA, L.P.; RODRIGUES, M.T.; GUIMARÃES, J.D. et al. Condição corporal ao parto e perfil metabólico de cabras Alpinas no início da lactação. Revista Brasileira de Zootecnia, v.38, n.10, p.2007-2014, 2009.

BARTLEY, E.E.; DEYOE, C.W. Starea as a protein replacer for ruminants - review of 10 years of research. Feedstuffs, v.47, p.42-44, 1975

BLOWEY, R.W. Blood metabolites. In: ANDREWS, A.H. (Ed) Bovine medicine: diseases and husbandry of cattle. 1.ed. Oxford: Blackwell, 1992. p.601-604.

BRODERICK, G.A.; CRAIG, W.M.; RICKER, D.B. Urea versus true protein as supplement for lactating dairy cows fed grain plus mixtures of alfafa and corn silages. Journal of Dairy Science, v.76, p.2266-2274, 1993.

CARMO, C.A.; SANTOS, F.A.P.; IMAIZUMI, H. et al. Substituição do farelo de soja por ureia ou amireia para vacas em final de lactação. Acta Scientiarum Animal Science, v.27, p.277-286, 2005.

FERNANDEZ, J.M.; SAHLU, T.; LU C.D. et al. Production and metabolic aspects of nonprotein nitrogen incorporation in lactation rations of dairy goats. Small Ruminant Research, v.26, p.105-107, 1997

FERNANDEZ, J.M.; CROOM JR., W.J.; TATE JR., L.P. et al. Subclinical ammonia toxicity in steers: Effects on hepatic and portal-drained visceral flux of metabolites and regulatory hormones. Journal of Animal Science, v.68, p.1726-1742, 1990.

GRAVERT, H.O. Dairy cattle production. Nova York: Elsevier Science, 1987. 234p.

GUIDI, M.T.; SANTOS, F.A.P.; BITTAR, C.M.M. et al. Efeito de fontes e teores de proteína sobre digestibilidade de nutrientes e desempenho de vacas em lactação. Acta Scientiarum Animal Science, v.29, p.325-331, 2007.

HELMER, L.G.; BARTLEY, E.E.; DEYOE, C.W. Feed processing. VI. Comparison of starea, urea, and soybean meal as protein sources for lactating dairy cows. Journal of Dairy Science, v.53, p.883-887, 1970

HUBER, J.T.; SANDY, R.A.; POLAN, C.E. et al. Varying levels of urea for dairy cow fed corn silage as the only forage. Journal of Dairy Science, v.50, p.1241-1247, 1967.

IMAIZUMI, H.; SANTOS, F.A.P.; PIRES, A.V. et al. Avaliação de diferentes fontes e teores de proteína na dieta sobre o desempenho, fermentação ruminal e parâmetros sanguíneos de 
vacas da raça Holandesa em final de lactação. Acta Scientiarum Animal Sciences, v.4, n.4, p.1031-1037, 2002.

IMAIZUMI, H.; SANTOS, F.A.P.; PIRES, A.V. et al. Fontes proteicas e de amido com diferentes degradabilidades ruminais para alimentar vacas leiteiras. Pesquisa Agropecuária Brasileira, v.41, p.1413-1420, 2006.

LU, C.D.; POTCHOIBA, M. J.; SAHLU, T. et al. Performance of dairy goats fed isonitrogenous diets containing soybean meal or hydrolyzed feather meal during early lactation. Small Ruminant Research, v.3, p. 425-434, 1990.

MATARAZZO, S.V.; MATTOS, W.R.S.; SUCUPIRA, M.C.A. et al. Teores de ureia em dietas com cana-de-açúcar: fermentação ruminal e concentrações de ureia plasmática em vacas leiteiras. Boletim da Indústria Animal, v.63, p.143-149, 2006.

MORAND-FEHR, P.; BAS, P.; BLANCHART, G. et al. Influence of feeding on goat milk composition and technological characteristics. In: MORAND-FEHR, P. Goat nutrition. Paris: Pudoc Wageningen, 1991. p.209-224.

NATIONAL RESEARCH COUNCIL - NRC. Nutrient requirement of goats: Angora dairy and meat goats in temperate and tropical countries. Washington: National Academy Press, 1981. 91p.

NATIONAL RESEARCH COUNCIL. Nutrient requirement of dairy cattle. Washington: National Academy Press, 2001. 381p

OLIVEIRA, A.S.; VALADARES, R.F.D.; VALADARES FILHO, S.C. Consumo, digestibilidade aparente, produção e composição do leite em vacas alimentadas com quatro níveis de compostos nitrogenados não proteicos. Revista Brasileira de Zootecnia, v.30, n.4, p.1358-1366, 2001.

OWENS, F.N.; ZINN, R. Protein metabolism of ruminants. In: CHURCH, C.D. The ruminant animal: digestive physiology and nutrition. New Jersey: Waveland Press, 1993. p.564.

PINA, D.S.; VALADARES FILHO, S.C.; VALADARES, R.F.D. et al. Consumo e digestibilidade aparente total dos nutrientes, produção e composição do leite de vacas alimentadas com dietas contendo diferentes fontes de proteína. Revista Brasileira de Zootecnia, v.35, n.4, p.1543-1551, 2006.

RINDSIG, R.B. Practical dairy goat feeding. Dairy Goat Journal, v. 55, p.12-19, 1977.

ROMAN-PONCE, H.; VAN HORN, H.H.; MARSHALL, S.P. et al. Complete rations for dairy cattle. V. Interaction of sugarcane bagasse quantity and form with soybean meal, urea, and starea. Journal of Dairy Science, v.58, n.9, p.1320-1327, 1975.

SAHLU, T.; FERNANDEZ, J.M.; JIA, Z.H. et al. Effect of source and amount of protein on milk production in dairy goats. Journal of Dairy Science, v.76, p.2701-2710, 1993a.
SAHLU, T.; HART, S.P.; FERNANDEZ, J.M. Nitrogen metabolism and blood metabolites in three goat breeds fed increasing amounts of protein. Small Ruminant Research, v.10, p.281-292, 1993 b.

SANTOS, F.A.P.; SANTOS, J.E.P.; THEURER, C.B. et al. Effects of rumen-undegradable protein on dairy cow performance: a 12-year literature review. Journal of Dairy Science, v.81, p.3182-3213, 1998a.

SANTOS, F.A.P.; HUBER, J.T.; THEURER, C.B. et al. Milk yield and composition of lactating cows fed steam-flaked sorgum and graded concentrations of ruminally degradable protein. Journal of Dairy Science, v.81, p.215-220, 1998b.

SANTOS, L.E.; BOSE, M.V. Produção de leite em caprinos alimentados com níveis crescentes de ureia. Boletim da Industria Animal, v.42, p.11-30, 1985.

SILVA, J.F.C.; PEREIRA, J.C.; VALADARES FILHO, S.C. et al. Valor nutritivo da palha de arroz suplementada com amireia, fubá + ureia e farelo de soja. Pesquisa Agropecuária Brasileira, v.29, p.1475-1481, 1994.

SILVA, M.G.C.M. Influência de fontes de nitrogênio na dieta de cabras Saanen, sobre o desempenho, concentrações de glicose e ureia no sangue e composição do leite. 2007. 104f. Tese (Doutorado em Zootecnia) - Universidade Federal de Lavras, Lavras.

STATISTICAL ANALYSIS SYSTEM - SAS. SAS/STAT: guide for personal computer. Version 9.1. Cary, 2003. 235p.

TANWAR, R.K.; TINNA, N.K.; GAHLOT, A.K. et al. Biochemical profile of clinical ketosis in goats. In: INTERNATIONAL CONFERENCE ON GOATS, 7., 2000, Tolouse. Anais... Toulouse, 2000, p.306-307.

TEIXEIRA, J.C.; SALVADOR, F.M. Amireia: uma revolução na nutrição de ruminantes. Lavras: UFLA/FAEPE, 2004. 174p.

Van SOEST, P.J. Use of detergents in the analysis of fibrous foods. II. A rapid method for the determination of fiber and lignin. Journal of Association of Official Analytical Chemists, v.46, p.829-835, 1963.

Van SOEST, P.J.; ROBERTSON, J.B.; LEWIS, B.A. Methods for dietary fiber, neutral detergent fiber, and nonstarch polysaccharides in relation to animal nutrition. Journal of Dairy Science, v.74, p.3583-3597, 1991.

VILELA, F.G.; TEIXEIRA, J.C.; PÉREZ, J.R.O. et al. Efeito da substituição do farelo de soja pela amireia $150 \mathrm{~S}$ no consumo, produção e composição do leite. Ciência Agrotécnica, v.31, n.5, p.1512-1518, 2007.

ZAMMIT, V.A. Role of insulin in hepatic fatty acid partitioning: emerging concepts. Biochemical Journal, v.314, p.1-14, 1996. 